\title{
Application of Six Sigma Methodology to Reduce Pseudo Soldering in SMT Process
}

\author{
Gang YANG \\ Nanjing SAC Automation Co., Ltd \\ Nanjing, China \\ E-mail: g-gang.yang@cn.abb.com
}

Jiu-Yu LI

Nanjing SAC Automation Co., Ltd

Nanjing, China

E-mail: jiuyu-li@sac-china.com

\section{Long-Sheng CHENG*}

School of Economics and Management

Nanjing University of Science and Technology

Nanjing, China

* Corresponding Author

E-mail: cheng_longsheng@163.com

\author{
Zhen-Hua HU \\ Nanjing SAC Automation Co., Ltd \\ Nanjing, China \\ E-mail: zhenhua-hu@sac-china.com
}

\author{
Lei XU \\ Nanjing SAC Automation Co., Ltd \\ Nanjing, China \\ E-mail: davis-lei.xu@sac-china.com
}

\begin{abstract}
In order to reduce the failure rate of SMT weld. Six Sigma methodology was used to analyze the solder joint faults in SMT, to determine the key quality characteristics, and to find out the key influencing factors of SMT process as the improvement focal point. The results demonstrated that the failure rate of SMT weld was greatly reduced after the improvement of the furnace temperature curve, the replacement of solder paste, the manual patch and PCB warp. The research also showed that six sigma methodology is a kind of scientific management method, which is suitable for wide application in the manufacturing industry.
\end{abstract}

\section{Keywords- SMT; Pseudo Soldering; Six Sigma}

\section{INTRODUCTION}

With the rapid changes in the electronics industry, Miniaturization, multi-functional, high reliability and other requirements for electronic system are getting higher, and Surface Mounting Technology (SMT) came into being. Different from the traditional cartridge technology, highdensity Printed Circuit Board (PCB) assembly with the application of SMT technology can effectively achieve "light, thin, short, small, and multi-functional." In the process of electronic assembly, pseudo soldering is a common problem, generally occurs in the case of oxidation at the point of welding and poor welding temperature. There is an isolation layer between the solder and the pins, which does not come into contact with each other to produce intermetallic compounds. The naked eye is generally unable to see its state, but its electrical properties are not conductive and affect the circuit characteristics, and become a problem in the electronics industry. In the veneer test process, pseudo soldering is serious, affecting the test of the storage time, resulting in inefficient production line.

Pseudo solder is one kind of familiar solder joint defect, and it is very difficult to be detected in SMT. In this manuscript, the quality of component, solder paste printing process, mounting processing, reflowing process, solder material are analyzed to illustrate the cause of pseudo solder in surface mounted technology[1]. parameter variations can occur during the deposition and printing of the soldering paste on a board, compromising its correct working[2].Wu Hong(2010) found that wrong welding order, wrong welding time and the fracture of welding hole in the welding process can result in pseudo soldering[3]. Luo Bing (2006) believes that pseudo soldering is mainly due to solder paste printing quality defects [4].

Since its introduction by Motorola in the 1980s, six sigma and its philosophy have found widespread application in many manufacturing industries [5]. The term "Six Sigma" has developed as an aspirational quality measure for organizational processes (a "good" organization usually being "four Sigma" or higher). Therefore, the main theme of Six Sigma is that of focusing on reducing variability in processes [6]. Six sigma utilizes the concept of statistical thinking and encourages the application of well-proven statistical tools and techniques for defect reduction through process variability reduction methods (e.g. statistical process control and design of experiment) [7]. Six Sigma has evolved into a set of well-established system approach to problem solving, and the Six Sigma-specific model that drives the continuous improvement of the enterprise is the DMAIC, which represents the five stages of the Six Sigma improvement, D (defined phase), M (measurement phase ), 
A (analysis phase), I (improvement phase), C (control phase) [8].

In this paper, the Six Sigma methodology is used to analyze the weld fault in SMT, determine the key quality characteristics, sort out the influence factors of SMT process, adopt the corresponding measures to improve and compare with the improvement to verify the improvement effect.

\section{CASE STUdy}

Pseudo Soldering, usually in the welding point of oxidation or impurity and welding temperature is poor, improper way to create, and its essence is the existence of solder and pin isolation layer, they are not fully contact with the metal Compounds, the naked eye is generally unable to see its state, but its electrical characteristics and no conduction or conduction failure, affecting the circuit characteristics, as the electronic assembly industry problems.

In the veneer test process, a quality pass rate feedback Weld problem is more obvious, affecting the test of the storage time, resulting in production line inefficient, and rework the quality of high cost. As the characteristics of Weld easy to bring the quality of the hidden dangers, will use the Six Sigma management related methods to carry out the project, to reduce the pseudo soldering in SMT process.

\section{A. Define Phase}

The aim of this phase is to reduce the pseudo soldering in SMT process and improve product qualification rate. According to the SMT fault distribution data from January to December in 2015, the fault category Pareto diagram was obtained. As is shown in the Pareto diagram, pseudo soldering, bridging and sealing off are the most important three kinds of faults, but the pseudo soldering is not easy to be found, causes the quality of higher risk, thus the goal of this project is to reduce the pseudo soldering.

The main customer of this project is the user and the managements of the company, the users want to buy stable and reliable products, while the managements hope to delivery on time with quality assurance and reduce rework costs. Therefore, the key to this project is to meet customer requirements, meet the requirements of functional testing and reduce the failure rate of operation and control, improve the test pass rate of failure. The team decided to consider the failure rate of SMT pseudo soldering as the Critical to Quality (CTQ) characteristic for this project, the failure rate defines as:

Failure rate $=$ Number of SMT pseudo soldering / Number of SMT fault plate

Since this project is a process optimization project, it was necessary to perform a SIPOC (Supplier-Input-ProcessOutput-Customer) analysis to have a better understanding of the process, SIPOC analysis as shown in Table 1.

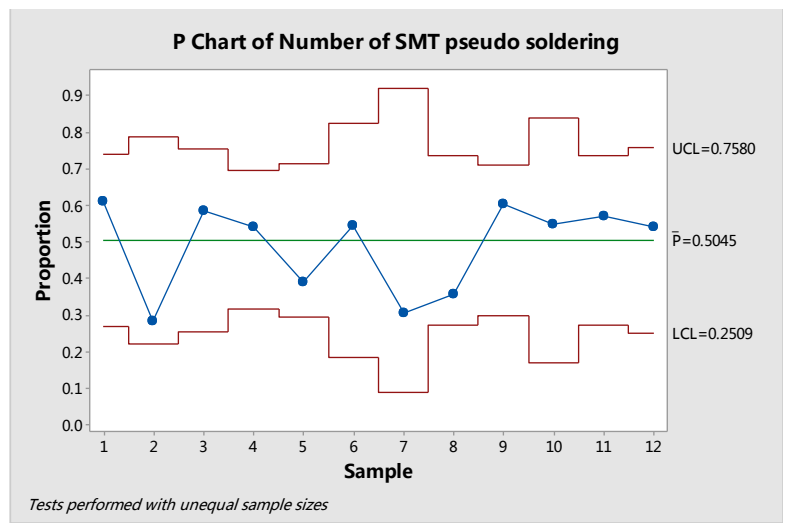

Figure 1. P Chart of Number of SMT pseudo soldering

\section{B. Measure Phase}

According to the SMT fault distribution data of 12 months, the stability of SMT pseudo soldering number can be observed from the P control chart (Figure 1). The results in P chart show that the proportion of SMT pseudo soldering number tends to be stable, no abnormal variation. At the same time, the analysis of process capability of SMT weld is obtained, the Index of Process Performance PPK value is only -0.14 , so it is necessary to further improve the process capability of the SMT weld.

\section{Analysis Phase}

According to the process flow of SMT, the influence factors of each stage are established as follows:

TABLE II THE INFLUENCE FACTOR IN SMT PROCESS FLOW PHASE

\begin{tabular}{|c|c|c|}
\hline Input(I) & Process(P) & Output(O) \\
\hline Device storage time & \multirow{4}{*}{ stores reserve } & \multirow{18}{*}{ Qualified PCBA } \\
\hline Device storage conditions & & \\
\hline PCB flatness & & \\
\hline Device pin planarity & & \\
\hline Ambient temperature & \multirow{6}{*}{ printing } & \\
\hline Ambient humidity & & \\
\hline The performance of solder paste & & \\
\hline Steel mesh opening & & \\
\hline Printing pressure & & \\
\hline Squeegee speed & & \\
\hline Mounting pressure & \multirow{4}{*}{ Patch } & \\
\hline Device planarity & & \\
\hline Manual patch & & \\
\hline Mounting quality & & \\
\hline Welding temperature curve & \multirow{2}{*}{ Reflow soldering } & \\
\hline Furnace stability & & \\
\hline Experience of inspectors & \multirow{2}{*}{ AIO test } & \\
\hline Window settings & & \\
\hline
\end{tabular}

Cause and effect analysis was conducted to identify the possible causes for untimely and inaccurate data as shown in Figure2.

TABLE I. TABLE 1 SIPOC ANALYSIS

\begin{tabular}{|c|c|c|c|c|}
\hline Supplier & Input & Process & Output & Customer \\
\hline $\begin{array}{l}\text { IQC, } \\
\text { Storage } \\
\text { Room }\end{array}$ & $\begin{array}{l}\text { Materials, equipment, } \\
\text { personnel, documents, } \\
\text { procedures }\end{array}$ & $\begin{array}{c}\text { Include three steps: Printing, patch, reflow } \\
\text { soldering }\end{array}$ & $\begin{array}{l}\text { Welded } \\
\text { PCDA }\end{array}$ & $\begin{array}{l}\text { Single board test } \\
\text { group }\end{array}$ \\
\hline
\end{tabular}

Note: IQC- incoming quality control, PCDA- printed circuit board assembly 


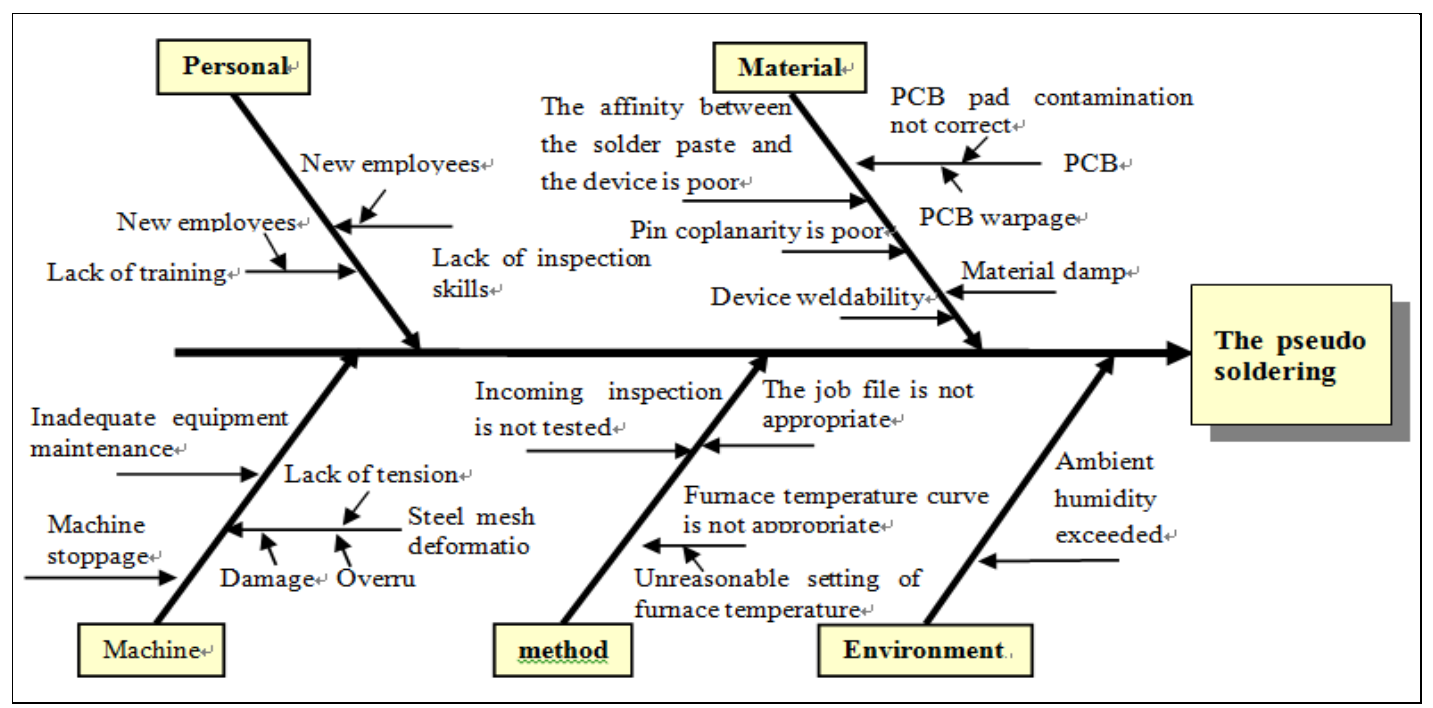

Figure 2. Cause and effect diagram

TABLE III THE IMPACT FACTOR SCORE

\begin{tabular}{|c|c|c|c|}
\hline \multicolumn{2}{|c|}{ Customer rating (1-10) } & 9 & \\
\hline \multirow{2}{*}{ Impact factor } & $\begin{array}{c}\text { Pseudo } \\
\text { soldering }\end{array}$ & Total \\
\hline Environment & $\begin{array}{c}\text { Ambient temperature } \\
\text { and humidity }\end{array}$ & 8 & $\mathbf{7 2}$ \\
\hline \multirow{4}{*}{ Device } & Device solder ability & 6 & 54 \\
\cline { 2 - 4 } & Lead coplanarity & 7 & 63 \\
\cline { 2 - 4 } & PCB warp & 9 & 81 \\
\cline { 2 - 4 } & Meta-material damp & 5 & 45 \\
\hline \multirow{4}{*}{ Printing } & $\begin{array}{c}\text { Solder ability of solder } \\
\text { paste }\end{array}$ & 9 & 81 \\
\cline { 2 - 4 } & Steel mesh opening & 2 & 18 \\
\cline { 2 - 4 } & Printing pressure & 3 & 27 \\
\cline { 2 - 4 } & Squeegee speed & 2 & 18 \\
\hline \multirow{4}{*}{ Patch } & Placement pressure & 2 & 18 \\
\cline { 2 - 4 } & Pad design & 3 & 27 \\
\cline { 2 - 4 } & Placement quality & 3 & 27 \\
\cline { 2 - 4 } & Manual patch & 8 & 72 \\
\cline { 2 - 4 } & Process flow & 4 & 36 \\
\hline \multirow{2}{*}{$\begin{array}{c}\text { Reflow } \\
\text { soldering }\end{array}$} & Furnace temperature \\
& curve & 4 & 36 \\
\cline { 2 - 4 } & Furnace stability & 4 & 36 \\
\hline \multirow{2}{*}{ AOI } & Personnel experience & 4 & 36 \\
\cline { 2 - 4 } & Window settings & 2 & 18 \\
\hline
\end{tabular}

According to the brainstorming listed in the impact of welding, 18 factors which affect the SMT process flow phase are selected and the scores are shown as shown in Table 3.

It was shown in Table 3 that there are four factors include ambient temperature and humidity, PCB warp, Solder ability of solder paste and manual patch scores total value greater than 70 , so, the four factors are selected as the key factors to reduce the pseudo soldering in SMT process.

\section{Improve Phase}

During the improvement phase, the team will be developing, implementing, and evaluating the solutions aimed at improving the causes verified in the analysis phase.
The goal of this phase is to demonstrate that the team's solutions actually solve the problem and lead to the desired improvement.

\section{1) Solutions for Optimizing the SMT Process}

Through the previous steps of DMAIC, four key factors were established. Every factor may lead to pseudo soldering in different ways, and we will analyze the corresponding solutions next.

\section{2) Solutions for Bad Soldering Paste}

Two main reasons lead to the bad soldering paste, one is that temperature curve was set unreasonable, which makes the soldering flux volatilized ahead of time. For this phenomenon, resetting the temperature curve and decreasing the growing rate may prevent the soldering flux from volatilizing too early.

The other reason is that activity of soldering flux is too low, which makes it easy volatile. In this paper, we changed the soldering paste A (BH63J878) for B (ALPHA LR721H3).

3) Solutions for Warp of PCB

Three main reasons lead to the warp of PCB. They are broken heat balance due to designing phase, $\mathrm{V}$-shaped deep cut of PCB and poor crafting. To keep heat balance, symmetry should be taken into consideration in the designing phase. To prevent warp caused by V-shaped deep cut, the first way is that the cutting depth should be confined at thickness of PCB's 1/3, the second way is to connect the plugins which require two-sided backflow by stamp hole, the third way is to check the warp more frequently after PCB's backflow. To avoid poor crafting, Incoming Quality Control (IQC) is applied into detecting the incoming materials, which confined the bowing and warping rate to $0.5 \%$.

4) Solutions for Temperature and Humidity's Exceeding

On one side, the main air-conditioning is not in use in May, June, October, and November, and the central air conditioning has a poor performance in regulating the regional temperature. For this phenomenon, two sets of airconditioning are added into SMT area separately and the 
cleaning work is done regularly, besides, we should regulate the air-conditioning's temperature when the temperature outside is above 28 degrees Celsius or below 22 degrees Celsius. On the other side, for the central air-conditioning is not able to dehumidify, we can add dehumidifiers in SMT area.

\section{5) Solutions for Optimizing the Manual Patch}

The main problem for the manual patch is lack of corresponding feeders, and tube feeding brings inconvenience in operation. Thus we proposed that suppliers should change the tube feeding for braid or disk feeders and provide more feeders or nozzles to improve the working efficiency. On the other side, different types of manual patches should have a corresponding minimum packaging quantity, which normalized the process of material purchasing.

\section{E. Control phase}

\section{1) Effect of Changing Soldering Paste}

We tracked different types of plugins in which soldering paste B (ALPHA LR721H3) is in use on E03-CPU.B-A, totaled 1120, and pseudo soldering is not found.

\section{2) Effect of Optimizing the Temperature and Humidity}

In the production of E02-CPU.F-B, pseudo soldering is declined from 3-5 times each month to 1 instance in the next two months.

\section{3) Effect of optimizing the Warp of $P C B$}

We controlled the warp after PCB's backflow, and plot the P-control chart before and after the optimization. It is clear that average warping degree is declined from $89.58 \%$ to $75 \%$, which shows the solutions are effective.

\section{(4) Effect of optimizing the Manual Patch}

The tube feeding may provide a good protection for the pins of components, but the poor stability and normalization lead to the low efficiency. When the disk feeders are applied into the production process, quality is more stable by checking the solder joints.

In the controlling phase, we work out some measures to strengthen the improving effect. First, the corresponding job files are modified and adjusted into fixed work by normalizing the optimizing solutions. Second, we trained the workers in production line based on the modified job files. Up to now, optimization in SMT process has been finished based on the theory of Six Sigma and satisfactory results have been obtained.

\section{CONCLUSIONS}

This paper analyzed the failure distribution of Nanjing SAC Automation Co., Ltd. from January to December in 2015, then determined the pseudo soldering as the research object, which is undetectable and high-risk in quality. Thus failure rate of pseudo soldering is regarded as CTQ and targets of this project are established. Based on the theory of Six Sigma, key factors influencing the SMT process are established after steps of defining, measuring and analyzing. Then optimizing plan are proposed corresponded to different key factors respectively. With the plan's carrying out, the failure rate is decreasing greatly and quality of solder joints has been highly improved.

The adoption of Six Sigma not only improved both the efficiency of the line and production capability, but also strengthened the customer loyalty by satisfying their needs and expectations. Applying Six Sigma to other areas besides manufacturing part can bring large benefit to the whole company.

\section{REFERENCES}

[1] [1] Wu, Fu Pei, Li, Sheng Ping. The Cause Analysis of Pseudo Solder in Surface Mounted Technology [J]. Advanced Materials Research, 2010, 146-147:895-898.

[2] [2] Acciani G, Fornarelli G, Giaquinto A. A Fuzzy Method for Global Quality Index Evaluation of Solder Joints in Surface Mount Technology [J]. Industrial Informatics IEEE Transactions on, 2011, 7(1):115-124.

[3] [3] Wu Hong. Weld case analysis [C] // 2010 China high-end SMT academic conference. 2010 .

[4] [4] Luo Bing, Zhong Liangji. SMT automatic detection based on machine vision [J]. Journal of Jingchu Institute of Technology, 2006, 21 (3): 29-31.

[5] [5] Chakrabarty A, Tan K C. The current state of six sigma application in services [J]. Journal of Service Theory \& Practice, 2012, 17(2):194208.

[6] [6] Mcadam R, Hazlett S. An absorptive capacity interpretation of Six Sigma [J]. Journal of Manufacturing Technology Management, 2010, volume 21(5):624-645.

[7] [7] Antony J. Some pros and cons of six sigma: an academic perspective [J]. TQM Magazine, 2013, 16(4):303-306.

[8] [8] Wang Yugan, Fan Shuhai, Pan Mi Mi, et al. Application of Six Sigma Management Based on Minitab in Energy Saving Lamp Assembly [J]. Industrial Engineering and Management, 2011, 16 (3): 131-137. 